\title{
CircRNA-0004904, CircRNA-0001855, and PAPP-A: Potential Novel Biomarkers for the Prediction of Preeclampsia
}

\author{
Min Jiang ${ }^{\mathrm{a}}$ Gendie E. Lash ${ }^{\mathrm{b}} \quad$ Xueqing Zhao Yan Long $^{\mathrm{a}} \quad$ Caijiao Guo $^{\mathrm{a}}$ \\ Hongling Yang ${ }^{\mathrm{a}}$ \\ aDepartment of Clinical Laboratory, Guangzhou Medical University Affiliated Guangzhou Women and \\ Children's Medical Center, Guangzhou, 'buangzhou Institute of Pediatrics, Guangzhou Women and \\ Children's Medical Center, Guangzhou, China
}

\section{Key Words}

CircRNA • PAPP-A • Preeclampsia

\begin{abstract}
Background/Aims: Circular RNAs (circRNAs) are transcribed prevalently in the genome; however, their potential roles in multiple cardiovascular diseases, particularly preeclampsia $(\mathrm{PE})$, are not yet well understood. This study investigated the expression profiles of circRNAs and explored circRNA-mediated pregnancy-associated plasma protein A (PAPP-A) expression as a potential biomarker for PE before 20 weeks of pregnancy. Methods: A nested case-control two-phase screening/validation study was performed in pregnant women before 20 weeks of gestation (before clinical diagnosis) at Guangzhou Women and Children's Medical Center from 2012 to 2015. In the screening phase, circRNA expression profiles of blood cells were assessed using a human circRNA microarray, which was designed to detect simultaneously 5396 circRNAs, in 5 patients with PE and 5 age- and gestational week-matched controls. In the validation phase, 18 circRNAs in blood cells predicted by bioinformatics tools were validated by quantitative reverse transcription PCR in a cohort of 60 patients (PE and age-, gestational week-, and sample storage time-matched controls). Then, we examined the involvement of circRNAs in PE-related pathways via interactions with miRNAs by multiple bioinformatics approaches. Bioinformatics analysis predicted that hsa_circ_0004904 and hsa_circ_0001855 miRNA sponges directly target PAPP-A. PAPP-A was verified in the serum of the same cohort of patients using an enzyme-linked immunosorbent assay. Finally, we combined PAPP-A with circRNAs to create a novel preclinical diagnostic model for PE with logistic regression and evaluated the efficiency of this model with receiver operating curve analysis. Results: Volcano plot analysis using various parameters showed that circRNAs were differentially expressed among both groups $(P<0.01$, fold change $>2)$. In the screening phase, we found that 2178 circRNAs were differentially expressed between the control and PE groups, in which 884 circRNAs were downregulated and 1294 circRNAs were upregulated in the PE group compared with the


control group. In the validation phase, two circRNAs, hsa_circ_0004904 and hsa_circ_0001855, were significantly upregulated in $\mathrm{PE}$ patients compared with healthy pregnant women $(P<$ 0.05). PAPP-A expression levels, related to the two circRNAs based on bioinformatics prediction, were increased in the PE group compared with the control group. The area under the curve of the combined model was 0.94 in the predicted PE subjects. Conclusions: This is the first study to report circRNA profiling in patients with PE prior to the onset of symptoms. Our data suggested that hsa_circ_0004904 and hsa_circ_0001855 combined with PAPP-A might be promising biomarkers for the detection of PE. Moreover, circRNAs may provide new insights into the potential mechanisms underlying the pathophysiology of PE.

(C) 2018 The Author(s)

Published by S. Karger AG, Basel

\section{Introduction}

Preeclampsia (PE), a pregnancy-specific disorder, is one of the most common obstetric disorders [1]. The global morbidity of PE is approximately 3-8\%, and it is the leading cause of pregnancy-related maternal and neonatal morbidity and mortality worldwide [2]. PE is typically characterized by new-onset hypertension ( $\geq 140 / 90 \mathrm{mmHg}$ ) after 20 weeks of gestation with proteinuria ( $\geq 0.3$ g protein in $24 \mathrm{~h}$ ). PE not only affects multiple organs (such as the lungs, liver, kidneys, and heart) and the neurological system of pregnant women, but also causes fetal intrauterine growth restriction, premature birth, death, and other effects [3]. Women with PE are at a greater risk of developing cardiovascular complications later in life. Although the clinical symptoms of patients with PE present after 20 weeks of gestation, the molecular events leading to its onset have been suggested to occur early in pregnancy. As many studies on the mechanism of PE are focused on polymorphisms or chronic hepatitis B infection, RNAs (circRNAs) are rapidly gaining prominence recently [4-7].

It has been shown that circular RNAs (circRNAs) are differentially expressed in the third trimester placenta of patients with PE compared with normal pregnant women and may be involved in PE [8]. CircRNAs are a newly described type of endogenous non-coding RNA that are gaining increasing attention in the field of regulatory RNA species. Compared with traditional linear RNA species (containing $5^{\prime}$ and $3^{\prime}$ ends), circRNA molecules have a closed loop structure, which is not easily degraded by exonuclease RNase R; hence, they are more stable than linear RNA [9-11]. It has been shown that circRNAs can function as microRNA (miRNA) sponges and also regulate the alternative splicing and expression of their parental genes [12-15]. For example, the circRNA ciRS-7/CDR1as (circRNA sponge for miR-7 or CDR1antisense) can reduce the expression of miR-7 target genes if CDR1as is silenced or miR-671 is overexpressed [12, 16]. Furthermore, Cocquerelle et al. demonstrated that circRNAs can have certain tissue and disease specificity [17]. Despite this increase in interest, the mechanism by which circRNAs underlie the pathogenesis of PE, more specifically, prior to the onset of symptoms, has been reported rarely. Moreover, a reliable biomarker for the early diagnosis of PE remains elusive.

Pregnancy-associated plasma protein A (PAPP-A), a macromolecular glycoprotein, is mainly synthesized by placental trophoblast cells and is then secreted into the blood. It is generally used as an index of the first-trimester screening test for Down's syndrome in pregnant women [18]. The amount of PAPP-A can reflect the level of hypoxia and ischemia of the placenta. PAPP-A is closely related to pregnancy because it plays an important role in trophoblast invasion by modulating the activity of insulin-like growth factor (IGF) through the cleavage of binding proteins [19-20]. Previous studies have shown that PAPP-A alters placental trophoblast differentiation and invasion by mediating IGF in the first trimester of pregnancy, which is associated with PE, miscarriage, preterm delivery, fetal growth restriction, and fetal death [21-24].

In this study, we assessed circRNA expression profiles in blood cells of patients with PE before the $20^{\text {th }}$ week of gestation and evaluated the efficacy of circRNAs and circRNAmediated PAPP-A for diagnosing PE before the onset of clinical symptoms, gaining a new insight into the role of circRNAs in the pathogenesis of PE.

\section{KARGER}




\section{Cellular Physiology Cell Physiol Biochem 2018;46:2576-2586 \begin{tabular}{l|l} 
and Biochemistry Published onlIne: May 14, 2018 & $\begin{array}{l}\text { ( ) 2018 The Author(s). Published by S. Karger AG, Basel } \\
\text { www.karger.com/cpb }\end{array}$ \\
\hline
\end{tabular}}

Jiang et al.: CircRNA and PAPP-a in Preeclampsia

\section{Materials and Methods}

\section{Subjects}

All of the women who underwent a prenatal examination and subsequently delivered at Guangzhou Women and Children's Medical Center (GWCMC), China, between April 2012 and July 2015, were enlisted in the study. The ethics committee of GWCMC approved all aspects of this study. Written informed consent was obtained from all subjects.

$\mathrm{PE}$ is characterized by new-onset hypertension and proteinuria after the $20^{\text {th }}$ week of gestation and is resolved by 6 weeks postpartum [25-26]. Blood pressure was documented in all subjects on 2 separate occasions that were at least $6 \mathrm{~h}$ apart. In the control group, the participants exhibited normal blood pressure without an excess of proteinuria, pregnancy complications, or other fetal malformations. In this study, we excluded women who had multiple pregnancies, gynecological disease, gestational diabetes mellitus, pregestational type 1 and type 2 diabetes, chronic hypertension, and cardiovascular, liver, or kidney diseases.

In the screening phase, 478 pregnant women were recruited, in which 5 developed PE in the later phase of gestation, who satisfied all the inclusion and exclusion criteria for the PE group, and the remaining participants were excluded. In the validation phase, 1889 pregnant women were recruited, and 30 of them who developed PE satisfied all the inclusion and exclusion criteria. The remaining subjects were excluded. In both sets, the pregnant women who developed PE were matched at a 1:1 ratio for age, gestational week, and sample storage date with controls who had pregnancy without complications. The details of the study design are given in Fig. 1.

\section{Specimen collection and preservation}

Maternal whole blood samples were obtained from a prospective cohort of unselected women before the $20^{\text {th }}$ week of gestation between April 2012 and July 2015 at GWCMC. Fresh peripheral venous blood samples ( $3 \mathrm{~mL}$ ) were collected and then centrifuged (3000 rpm for $10 \mathrm{~min}$ at room temperature). Subsequently, the plasma and blood cells were separated immediately and stored at $-80^{\circ} \mathrm{C}$ until use.

\section{Human circRNA microarray analysis}

The 5396 labeled circRNAs were hybridized on an Arraystar Human circRNA Array (catalog \# ASCR-001, 8 × 15 K; Arraystar, Rockville, MD, USA). Microarray procedures and data analyses were performed at Kangchen Corporation (Shanghai, China). Briefly, the experiment consisted of the following 5 steps. (1) Total RNA extraction: total RNA from peripheral blood mononuclear cells was extracted using the TRIzol LS Reagent (Invitrogen, Karlsruhe, Germany), following the manufacturer's instructions; (2) total RNA quality: total RNA quality of the samples was measured using NanoDrop ND-1000 RNA quantity and quality assessment, and RNA integrity was assessed through standard denaturing gel electrophoresis; (3) RNA labeling: labeling was conducted using an Arraystar Super RNA Labeling Kit according to the manufacturer's instructions, and the total RNA of each sample was amplified using a random primer and reverse transcribed to fluorescencelabeled cRNA; (4) chip hybridization: fluorescence-labeled circRNAs were measured using an Arraystar Human circRNA Array through hybridization and subsequent incubation in an Agilent hybridization oven at $65^{\circ} \mathrm{C}$ for $17 \mathrm{~h}$; and (5) chip scanning: after washing the chips, they were scanned using an Axon GenePix 4000B Scanner and imported into GenePix Pro 6.0 software (Axon, Foster City, CA, USA).

The CircRNA chip data acquisition and analysis process was as follows. First, the original data extraction was conducted by adding the chip scanning image to GenePix Pro 6 software and reading the original data. Next, circRNA

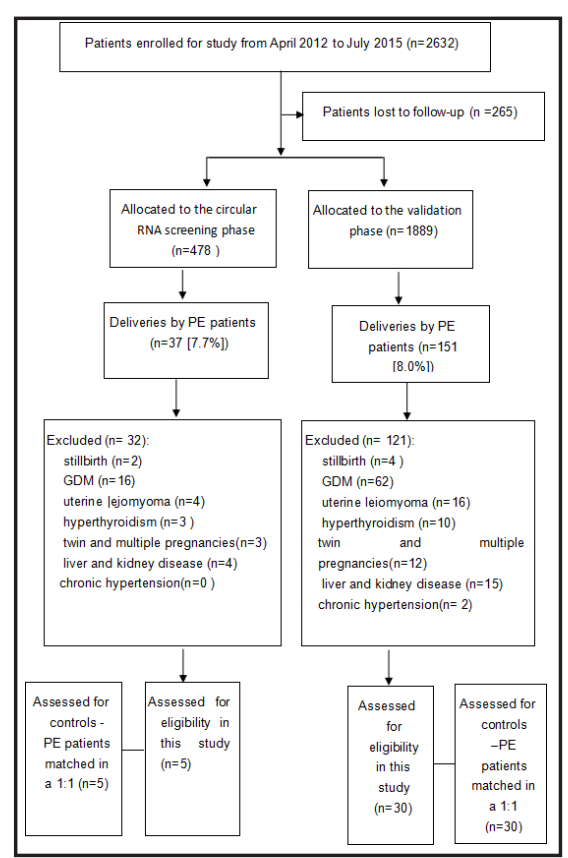

Fig. 1. Study design. 
expression profiling was performed using the R software package for data normalization and subsequent data processing. Third, the differential expression of circRNAs between both groups was evaluated by assessing the change in P-value and fold change (FC).

\section{Quantitative reverse transcription $P C R$}

Quantitative reverse transcription PCR (qRT-PCR) was performed with a TIANScript RT Kit (\#KR104; Tiangen, Beijing, China) and Talent SYBR Green qPCR Premix (\#FP209; Tiangen, Beijing, China) following the manufacturer's instructions. Divergent primers, instead of the more commonly used convergent primers, were designed. On the basis of the largest FC $(>40)$ and the P-value $(<0.001)$, we selected 9 circRNAs as validation genes. The primers for the validation of circRNAs and $\beta$-actin were synthesized by the Longsee Biomedical Company (Guangzhou, China). The sequences of $\beta$-actin and paired primers are shown in Table 1.

The reaction conditions for the 2 circRNAs were as follows. For hsa_circ_0001855 (FC = 45.77): initial denaturation at $95^{\circ} \mathrm{C}$ for $3 \mathrm{~min}$; followed by 39 cycles at $95^{\circ} \mathrm{C}$ for $5 \mathrm{~s}$, pre-selected annealing temperature for $30 \mathrm{~s}$, and $72^{\circ} \mathrm{C}$ for $20 \mathrm{~s}$; and final extension at $72^{\circ} \mathrm{C}$ for $10 \mathrm{~min}$. For hsa_circ_0004904 (FC = 47.33): initial denaturation at $95^{\circ} \mathrm{C}$ for $3 \mathrm{~min}$; followed by 39 cycles at $95^{\circ} \mathrm{C}$ for $15 \mathrm{~s}$, pre-selected annealing temperature for $30 \mathrm{~s}$, and $72^{\circ} \mathrm{C}$ for $25 \mathrm{~s}$; and final extension at $72^{\circ} \mathrm{C}$ for $10 \mathrm{~min}$. The data were analyzed by the $\Delta \Delta \mathrm{C}_{\mathrm{T}}$ method. The experiments were performed independently three times.

\section{Enzyme-linked immunosorbent assay}

PAPP-A reportedly plays an important role in trophoblast differentiation and invasion during early pregnancy. Moreover, bioinformatics analysis predicted that circRNA_0001855 and circRNA_0004904, as well as their miRNA sponges, including miR-29a-5p, miR-765, miR-134-3p, miR-623, miR-138-5p, miR-30c1-3p, and miR-30c-2-3p, directly target PAPP-A. Hence, its expression in plasma was assessed using enzymelinked immunosorbent assay (ELISA) (catalog no. CS-human PAPP-A; Chemical Biology Test Systems, Shanghai, China) according to the manufacturer's instructions. The lowest detectable PAPP-A concentration was $6.25 \mathrm{pg} / \mathrm{mL}$.

\section{Statistical analysis}

The data were analyzed by SPSS version 17.0 for Windows (SPSS Inc., Chicago, IL, USA) and GraphPad Prism (version 6.0) software. Continuous variables with a normal distribution are presented as mean (standard deviation), and nonnormal variables are reported as median (inter quartile range). Means of two continuous normally distributed variables were compared by paired samples using Student's $t$-test. The MannWhitney $U$ test and KruskalWallis test were, respectively, used to compare the means of two variables not normally distributed. The frequencies of categorical variables were compared using Pearson's $\chi^{2}$ or Fisher's exact test, whenever appropriate. A value of $\mathrm{P}$ $<0.05$ was considered statistically significant.

The miRNA sponges of the circRNAs were predicted in the assay by software from the Arraystar Company (based on miRanda \& TargetScan).

Table 1. Sequences of $\beta$-actin and the paired primers of 18 circRNAs

\begin{tabular}{|c|c|c|}
\hline & $5^{\prime}-3^{\prime}$ (sense) & 5'-3' (antisense) \\
\hline$\beta-$ actin & AGCGAGCATCCCCCAAAGTT & GGGCACGAAGGCTCATCATT \\
\hline hsa_circ_0009109 & AACCAACAGACAATGCCAATTTAC & CCATCTCCAGAGCAGGATACAA \\
\hline hsa_circ_0031787 & CCTGATGAAAGCGGAAGCA & GCCTGTGGGTCCTCTGGTG \\
\hline hsa_circ_0004001 & TCACAGTACATTGGTATCTACAAGACATT & CTGGATTTATTAAGGTGCGTTCAT \\
\hline hsa_circ_0062813 & AAGAGACTGAACAACGCAATCC & TATCTCGGCATTCAACACTTTCTA \\
\hline hsa_circ_0003410 & ACAGATGCGTCTCGCTCAAGT & TGCGTTGATTGTGCTGCTG \\
\hline hsa_circ_0067504 & GCCTGCGTACCATCTTCACC & AGCAAGACTTCCCAACACCACT \\
\hline hsa_circ_0023904 & TGGGCAATCTTGGCATCG & GTGGGAGTTTGGCAACAGGA \\
\hline hsa_circ_0042852 & GAAACTCCAGAACAAACATCAAAAG & TATTGGTGCTATGAGATTCCGAG \\
\hline hsa_circ_0044195 & TTACAGAACTCAGCTTTGGAACATT & TCTAAATACTGGAGGGATAGCAGG \\
\hline hsa_circ_0001855 & CACTTCTCAGGGGAACGATGC & CTGGTGATGCTGATGTATAATCAAAG \\
\hline hsa_circ_0001965 & GCCTGGAATCACGAAGCACA & CCAACTTCTGGCTGCGTAATGT \\
\hline hsa_circ_0004904 & GATAAAGCAGAGATGTTTCGTGAGC & TACACAAAGCGTGGAATATCAAATG \\
\hline hsa_circ_0002903 & GAGTTCAAGTTCAAAGAGAGCGAG & TCCTCCATTTCTGATTGATGCTT \\
\hline hsa_circ_0008995 & ATCGGAAACTACAGACTGTTGAAAAC & GAGGTAACTTCTTGACGCCCAT \\
\hline hsa_circ_0002629 & TTGCCAAACCTCTTGCCACTA & GGACATTCTTCCATTTCCTGC \\
\hline hsa_circ_0001819 & CCTGGTAGGACAAGCGACTCTC & AATAGTAGCCTGTTCCAATACATTCAAA \\
\hline hsa_circ_0035226 & TAGAAGGCCATCTACCGAAGACA & ACAGTCAGTAAATCCAGCAAGAGAAC \\
\hline hsa_circ_0005720 & TTGTACTGAAAAATGGAGTGCTGG & GCAGTTTTGTGTTGATCTCCATATTT \\
\hline
\end{tabular}


The discriminatory performance of the circRNAs associated with PE was assessed using receiver operating characteristic analysis.

\section{Results}

\section{Characteristics of the} study participants

The demographic characteristics of the study participants are presented in Table 2. No differences in height, primigravida, education $>12$ years, and history of spontaneous abortion $(\geq 1)$ were noted between both groups. However, weight and body mass index before pregnancy, systolic/diastolic blood pressure before the $20^{\text {th }}$ week of gestation, anemia in pregnancy, gestational age at delivery, birth weight of infants, and infant delivery at $<37$ weeks were significantly different between both groups $(\mathrm{P}<0.05)$.

\section{CircRNA microarray screening}

To assess the differ-

Table 2. Demographic characteristics of the study participants with PE and the controls with normal pregnancy, and characteristics of their infants. Note: *Women who developed PE and women who had a normal pregnancy were matched by age and gestational week. ${ }^{*} \mathrm{P}<0.05$ vs. Control

\begin{tabular}{|c|c|c|c|c|c|c|}
\hline \multirow[b]{2}{*}{ Characteristic } & \multicolumn{3}{|c|}{ The circular RNA screening phase } & \multicolumn{3}{|c|}{ The circular RNA and PAPP-A validation phase } \\
\hline & $\begin{array}{l}\text { Controls } \\
(\mathrm{N}=5)\end{array}$ & $\begin{array}{c}\text { Women with PE } \\
(N=5)\end{array}$ & $\begin{array}{c}\mathbf{P} \\
\text { Value }\end{array}$ & $\begin{array}{l}\text { Controls } \\
(\mathrm{N}=30)\end{array}$ & $\begin{array}{l}\text { Women with PE } \\
\qquad(\mathrm{N}=\mathbf{3 0})\end{array}$ & $\begin{array}{c}P \\
\text { Value }\end{array}$ \\
\hline \multicolumn{7}{|l|}{ Women } \\
\hline Age--yr & $27 \pm 3.00$ & $26.2 \pm 3.0$ & 0.338 & $29.6 \pm 2.0$ & $29.7 \pm 3.0$ & 0.408 \\
\hline Height--cm & $159.0 \pm 6.8$ & $164.0 \pm 1.4$ & 0.18 & $161.1 \pm 4.6$ & $160.2 \pm 4.6$ & 0.516 \\
\hline Weight--kg & $47.1 \pm 3.0$ & $56.2 \pm 4.2$ & 0.027 & $49.5 \pm 5.9$ & $53.8 \pm 6.6$ & 0.009 \\
\hline $\begin{array}{l}\text { Pre-pregnancy body-mass } \\
\text { index }\left(\mathrm{kg} / \mathrm{m}^{2}\right)\end{array}$ & $18.7 \pm 2.2$ & $22.2 \pm 3.0$ & 0.167 & $19.1 \pm 2.0$ & $20.9 \pm 1.9$ & $<0.01$ \\
\hline Systolic blood pressure $-\mathrm{mm} \mathrm{Hg}$ & $104.6 \pm 9.6$ & $117.6 \pm 7.9$ & 0.043 & $105.7 \pm 10.5$ & $115.0 \pm 5.8$ & $<0.01$ \\
\hline Diastolic blood pressure $-\mathrm{mm} \mathrm{Hg}$ & $63.2 \pm 8.4$ & $70.8 \pm 8.3$ & 0.246 & $63.9 \pm 7.7$ & $73.9 \pm 6.9$ & $<0.01$ \\
\hline Anemia & 0 & 1 & 0.5 & 4 & 11 & 0.036 \\
\hline Primigravida - no. (\%) & 2 & 2 & 0.738 & 18 & 16 & 0.397 \\
\hline Gestational age at delivery - days & $276.4 \pm 6.9$ & $262.4 \pm 11.1$ & 0.048 & $278.1 \pm 5.4$ & $264.2 \pm 17.9$ & $<0.01$ \\
\hline Education $>12$ years & 6 & 6 & 1 & 29 & 27 & 0.306 \\
\hline \multicolumn{7}{|l|}{ Infants } \\
\hline Birth weight $-\mathrm{g}$ & $3222.0 \pm 272.8$ & $2762.0 \pm 313.7$ & 0.1 & $3204.0 \pm 352.2$ & $2825.8 \pm 706.6$ & 0.006 \\
\hline History of spontaneous abortion ( $\geq 1$ ) & 0 & 0 & 1 & 3 & 3 & 0.665 \\
\hline \multicolumn{7}{|l|}{ Specimens } \\
\hline Freezer storage $-80^{\circ} \mathrm{C}-\mathrm{yr}$ & $2.0 \pm 0.5$ & $1.6 \pm 0.5$ & 0.092 & $2.3 \pm 0.23$ & $2.4 \pm 0.23$ & 0.14 \\
\hline
\end{tabular}
ential expression levels of circRNAs in peripheral blood cells from pregnant women with PE before the $20^{\text {th }}$ week of gestation, a human circRNA microarray was utilized. Volcano plots (Fig. 2A) and heat maps (Fig. 2B) at different P-values and $\mathrm{FC}$ revealed that 2178 circRNAs were significantly dif-

Fig. 2. Assessment of circRNA expression profiles in the screening phase. (A) Volcano plots ( $\mathrm{FC}>2, \mathrm{P}<0.01$ ). The red blocks indicate differentially expressed circRNAs; gray blocks indicate circRNAs with no difference in their expression.

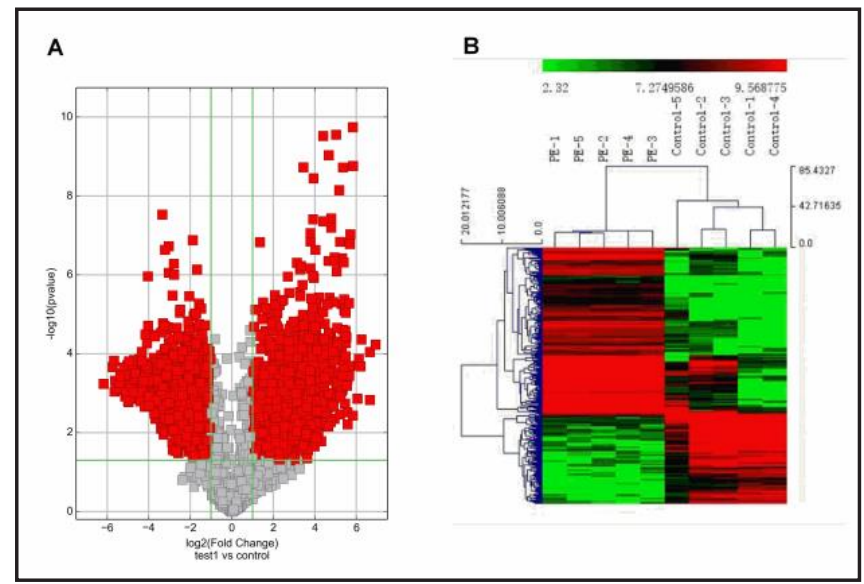
Hierarchical cluster analysis: circRNA expression profiles in PE of the 10 samples in red (high relative expression) or green (low relative expression) scale. ferentially ex- 
pressed (FC > 2.0; $\mathrm{P}<0.05$ ), including 1294 upregulated circRNAs and 884 downregulated circRNAs, when compared between both groups. Only the circRNAs with FC $>40$ and $\mathrm{P}<0.001$ are shown in Table 3. In the hierarchical clustering analysis shown in Fig. 2B, red or green represented upregulated or downregulated circRNAs, respectively.

Validation of circRNAs by qRTPCR

In the validation phase, we selected pregnant women from another cohort and confirmed the expression levels of 18 circRNAs (Fig. 3) in peripheral blood cells using qRT-PCR, based on FC $>40$ and $\mathrm{P}<0.001$. As shown in Fig. 4, for the 18 circRNAs, the expression levels of hsa circ_0001855 and hsa_circ_0004904 were markedly increased in women with PE compared with matched healthy women in the validation set $(\mathrm{P}<0.05)$.

miRNA recogni-
tion element pre-
diction for cir-
CRNA_0001855
and r cir-
CRNA_0004904

On the basis on the interaction between cir-
Table 3. Circular RNAs that were significantly differentially expressed in maternal blood cells $(\mathrm{FC}>40, \mathrm{P}<0.001)$

\begin{tabular}{|c|c|c|c|c|c|c|c|c|}
\hline Alias & P-value & FDR & FC (abs) & Regulation & circRNA_type & chrom & strand & GeneSymbol \\
\hline hsa_circ_0006732 & 5.86479E-05 & 0.001100545 & 121.2588413 & up & Exonic & chr13 & - & ZDHHC20 \\
\hline hsa_circ_0057552 & 0.001486878 & 0.005309453 & 100.6040815 & up & Exonic & chr2 & + & SLC39A10 \\
\hline hsa_circ_0001439 & $9.03812 \mathrm{E}-05$ & 0.001313921 & 100.2724866 & up & Exonic & chr4 & - & SCLT1 \\
\hline hsa_circ_0037078 & 4.35113E-05 & 0.000958539 & 75.9614983 & up & Exonic & chr15 & + & LRRK1 \\
\hline hsa_circ_0042852 & 0.000208804 & 0.001910404 & 73.3371923 & up & Exonic & chr17 & + & SUZ12P1 \\
\hline hsa_circ_0044195 & 0.00013524 & 0.00159597 & 69.4833931 & up & Exonic & chr17 & + & LRRC37A \\
\hline hsa_circ_0004001 & 0.000197945 & 0.001870362 & 66.6524343 & up & Exonic & chr2 & - & CLK1 \\
\hline hsa_circ_0092232 & 0.001365671 & 0.005058347 & 66.3636049 & up & Exonic & $\operatorname{chrY}$ & + & USP9Y \\
\hline hsa_circ_0003410 & $1.73 \mathrm{E}-09$ & 0.000000993 & 57.0272929 & up & Exonic & chr9 & - & UBAP2 \\
\hline hsa_circ_0023904 & $1.8 \mathrm{E}-10$ & 0.000000368 & 56.6717666 & up & Exonic & chr11 & - & PICALM \\
\hline hsa_circ_0067934 & 0.003679557 & 0.009951038 & 56.6697599 & up & Exonic & chr3 & + & PRKCI \\
\hline hsa_circ_0067504 & $9.414 \mathrm{E}-08$ & 0.00002164 & 52.1486976 & up & Exonic & chr3 & + & ARMC8 \\
\hline hsa_circ_0062813 & $1.6479 \mathrm{E}-07$ & 0.000028862 & 51.5001332 & up & Exonic & chr22 & + & MTMR3 \\
\hline hsa_circ_0009109 & 0.000204745 & 0.001887239 & 51.149794 & up & Exonic & chr1 & + & DCAF6 \\
\hline hsa_circ_0031787 & 0.000360443 & 0.002437261 & 50.3835967 & up & Exonic & chr14 & - & POLE2 \\
\hline hsa_circ_0000793 & $5.20049 \mathrm{E}-06$ & 0.000319729 & 49.8024618 & up & Exonic & chr17 & - & USP32 \\
\hline hsa_circ_0013048 & 0.006135741 & 0.014531394 & 47.6187214 & up & Exonic & chr1 & + & LPHN2 \\
\hline hsa_circ_0004166 & 0.003053978 & 0.008660393 & 47.572918 & up & Exonic & chr14 & + & TRAF3 \\
\hline hsa_circ_0004904 & 0.000434388 & 0.002671702 & 47.331447 & up & Exonic & chr14 & - & POLE2 \\
\hline hsa_circ_0007587 & 0.000640251 & 0.003261364 & 46.569681 & up & Exonic & chr6 & + & ZNF451 \\
\hline hsa_circ_0001855 & $3.74305 \mathrm{E}-05$ & 0.000911717 & 45.7685829 & up & Exonic & chr9 & - & RNF38 \\
\hline hsa_circ_0008394 & $5.36878 \mathrm{E}-05$ & 0.001039283 & 44.976176 & up & Exonic & chr3 & + & TIMMDC1 \\
\hline hsa_circ_0001790 & 0.000115737 & 0.001498938 & 44.7148914 & up & Exonic & chr8 & + & ASH2L \\
\hline hsa_circ_0070933 & 7.31313E-06 & 0.000384253 & 44.617766 & up & Exonic & chr4 & + & LARP1B \\
\hline hsa_circ_0035226 & $9.0324 \mathrm{E}-06$ & 0.000437169 & 44.5876405 & up & Exonic & chr15 & - & TRPM7 \\
\hline hsa_circ_0001819 & $2.5939 \mathrm{E}-05$ & 0.000763229 & 44.3994845 & up & Exonic & chr8 & - & UBR5 \\
\hline hsa_circ_0008995 & 0.000265746 & 0.002108841 & 44.2641534 & up & Exonic & chr14 & + & MARK3 \\
\hline hsa_circ_0005720 & 3.62173E-05 & 0.000902727 & 43.7226751 & up & Exonic & chr1 & + & TMEM56 \\
\hline hsa_circ_0033480 & 0.00183314 & 0.006014531 & 43.6520117 & up & Exonic & chr14 & + & MARK3 \\
\hline hsa_circ_0017972 & 7.92426E-06 & 0.000399252 & 42.6740774 & up & Exonic & chr10 & - & PIP4K2A \\
\hline hsa_circ_0007272 & 0.000149459 & 0.00165661 & 42.5585094 & up & Exonic & chr17 & - & USP32 \\
\hline hsa_circ_0001771 & $4.17971 \mathrm{E}-06$ & 0.000284685 & 42.4257885 & up & Exonic & chr7 & + & RBM33 \\
\hline hsa_circ_0008106 & 0.000242549 & 0.002041412 & 42.0836902 & up & Exonic & chr3 & + & LRCH3 \\
\hline hsa_circ_0086736 & $4.8219 \mathrm{E}-07$ & 0.000060547 & 41.7811286 & up & Exonic & chr9 & - & UBAP2 \\
\hline hsa_circ_0002629 & $1.89 \mathrm{E}-09$ & 0.000000993 & 40.7557409 & up & Exonic & chr17 & + & SUZ12 \\
\hline hsa_circ_0001965 & $4.78328 \mathrm{E}-05$ & 0.001000098 & 40.6679737 & up & Exonic & chr3 & - & PHC3 \\
\hline hsa_circ_0002903 & $2.4588 \mathrm{E}-05$ & 0.000741267 & 40.5546982 & up & Exonic & chr21 & + & PCNT \\
\hline hsa_circ_0007099 & 0.000813857 & 0.003723092 & 40.1428482 & up & Exonic & chr15 & + & ABHD2 \\
\hline hsa_circ_0001506 & 0.00057967 & 0.003103388 & 72.2475933 & down & Intronic & chr5 & - & SERINC5 \\
\hline hsa_circ_0001974 & 0.00021562 & 0.001934326 & 53.4197768 & down & Exonic & chr3 & - & TKT \\
\hline hsa_circ_0009143 & 0.000149536 & 0.00165661 & 51.0444781 & down & Exonic & chr8 & + & PVT1 \\
\hline hsa_circ_0080212 & 0.000904218 & 0.003950104 & 50.214327 & down & Exonic & chr7 & - & GRB10 \\
\hline hsa_circ_0028502 & 0.000483415 & 0.002826711 & 49.4042734 & down & Exonic & chr12 & - & SLC24A6 \\
\hline hsa_circ_0000602 & 0.000760732 & 0.003582699 & 46.6191475 & down & intragenic & chr15 & - & MY05A \\
\hline hsa_circ_0092304 & 0.000558465 & 0.003047529 & 42.9473714 & down & Intronic & chr3 & + & RPL35A \\
\hline hsa_circ_0007958 & 0.000362226 & 0.002437261 & 41.5023962 & down & Exonic & chr5 & + & RARS \\
\hline hsa_circ_0072788 & 0.000317423 & 0.002302728 & 40.3570872 & down & Exonic & chr5 & + & RAD17 \\
\hline
\end{tabular}


Fig. 3. Histogram for 18 circRNAs in blood cells in the validation phase. The levels of hsa_circ_0001855 and hsa_circ_0004904 were significantly higher in the PE group than in the control group $\left({ }^{* *} \mathrm{P}<0.05\right)$. Lower $\Delta \mathrm{C}_{\mathrm{T}}$ values signify higher levels of expression.

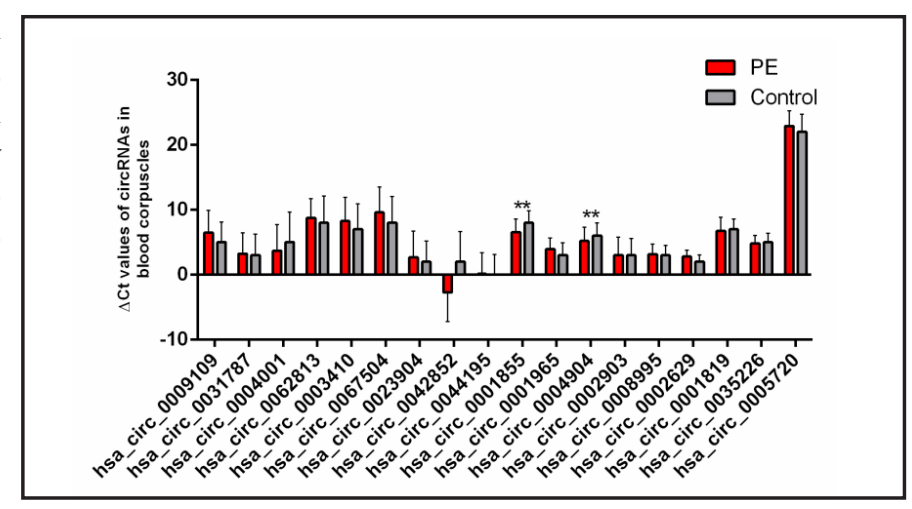

Fig. 4. MRE prediction of circRNAs indicates that circRNA_0001855 and circRNA_0004904 regulate the RNA transcripts of PAPP-A by competing for shared microRNAs.

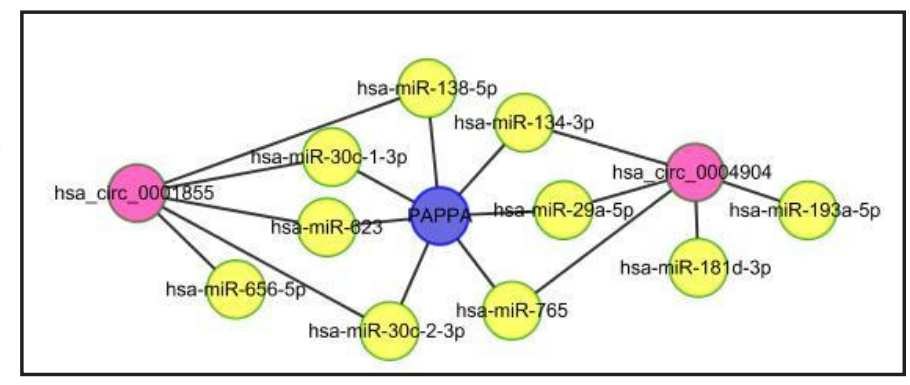

Fig. 5. Expression levels of hsa circ_0001855 and hsa_circ_0004904 in blood cells and those of PAPP-A in serum in the validation phase. (A) Expression of hsa_circ_0001855 (FC = 5.6) was significantly higher in patients with PE than in the controls
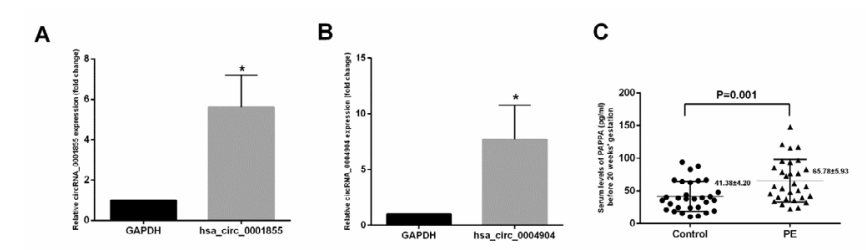
$\left({ }^{*} \mathrm{P}<0.01\right)$ as determined by qRT-PCR.

(B) Expression of hsa_circ_0004904 (FC $=7.7$ ) was significantly higher in patients with PE than in controls $\left({ }^{*} \mathrm{P}<0.01\right)$ as determined by qRT-PCR. (C) Women with PE showed significantly higher serum PAPP-A levels than controls $(\mathrm{P}=0.001)$.

cRNA_0001855, circRNA_0004904, and their miRNA sponges (miR-29a-5p, miR-765, miR134-3p, miR-181d-3p, miR-623, miR-138-5p, miR-30c-1-3p, miR-656-5p, and miR-30c-2$3 p$ ), the probable binding sites between the sponge miRNAs and their target genes were predicted using bioinformatics tools (TargetScan and miRanda). The results showed that PAPP-A correlated with most of the miRNA sponges among the lists of both prediction programs (Fig. 4). PAPP-A was thus accepted as a pivotal element in the early differentiation of placental trophoblast cells for elucidating the pathogenesis of PE.

\section{Validation of PAPP-A levels by ELISA}

The results implied that pregnant women who later developed PE had significantly increased PAPP-A levels before the $20^{\text {th }}$ week of gestation compared with the corresponding healthy pregnant women (65.78 versus $41.38 \mathrm{pg} / \mathrm{mL}$, respectively, $\mathrm{P}<0.05$, Fig. $5 \mathrm{C}$ ). The above results suggest that circRNA_0001855 and circRNA_0004904 may negatively regulate miRNA sponges and upregulate PAPP-A expression. PAPP-A, the target gene of the circRNA_0001855 and circRNA_0004904 miRNA sponges, promotes trophoblast differentiation toward the invasive pathway in pregnancy.

Predictive performance of the circRNAs and PAPP-A

The area under the curve (AUC) of hsa_circ_0001855 was 0.621 (95\% confidence interval [CI] 0.478-0.764); its sensitivity and specificity were 53.33 and $70.00 \%$, respectively; and 


\section{Cellular Physiology Cell Physiol Biochem 2018;46:2576-2586 and Biochemistry Published online:'May 14, $2018 \quad \begin{aligned} & \text { DOI 10159/D2018 The Author(s). Published by S. Karger AG, Basel } \\ & \text { www.karger.com/cpb }\end{aligned}$ Jiang et al.: CircRNA and PAPP-a in Preeclampsia}

the cut-off value was 7.13 (cycle threshold $\left[\mathrm{C}_{\mathrm{T}}\right]$ value). The predictive performance of hsa_circ_0004904 was similar to that of hsa_circ_0001855; however, using plasma protein PAPP-A as a single predictor yielded $76.67 \%$ sensitivity, $\quad 60.00 \%$ specificity, $39.67 \mathrm{pg} / \mathrm{mL}$ cut-off value, and 0.728 AUC (95\% CI 0.601-0.855) in PE. When PAPP-A was utilized in combination with hsa circ_0001855 and hsa_circ_0004904, the AUC was markedly improved to 0.940 (95\% CI $0.869-1.000$ ), with $86.67 \%$ sensitivity and $96.67 \%$ specificity (Fig. 6).

\section{Discussion}

The present study documented the circRNA expression profiles of blood cells before the $20^{\text {th }}$ week of gestation in women with PE for the first time. Although circRNAs have frequently been reported to be formed due to incorrect splicing during transcription, substantial evidence has suggested that they adsorb miRNAs during transcription, blocking their inhibitory effect

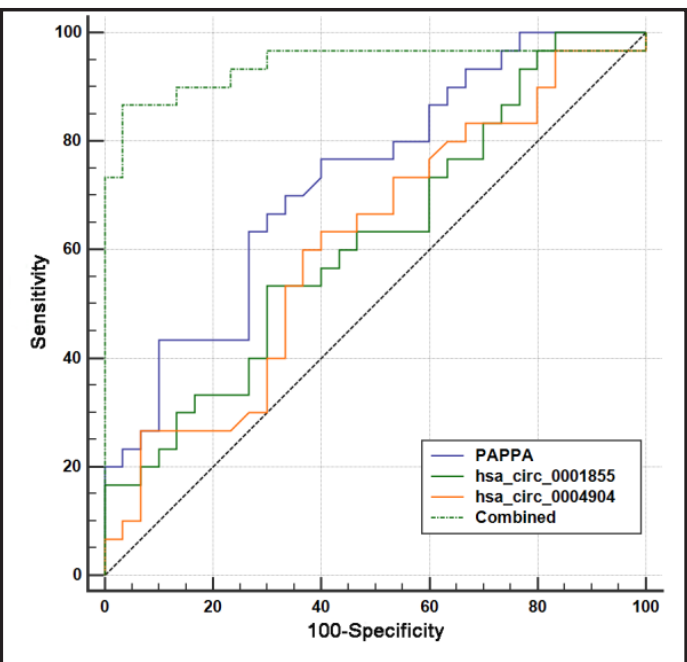

Fig. 6. Receiver operating characteristic curves showed that serum protein PAPP-A levels combined with circRNAs improved the possibility of early PE detection in pregnant women. CircRNA_0001855: AUC 0.621 (95\% CI 0.478-0.764); circRNA_0004904: AUC 0.611 (95\% CI 0.466-0.756); PAPP-A alone: AUC 0.728 (95\% CI 0.601-0.855); and combination model (PAPP-A + circRNAs): AUC 0.940 (95\% CI 0.869-1.000). on target mRNAs, thereby regulating mRNA expression. Moreover, several studies have indicated that circRNAs can act as molecular sponges that bind miRNAs, which have been implicated in various biological functions.

It was not until 1993 that scientists discovered numerous circRNAs [17] in human cells, but nowadays, the widespread and substantial presence of circRNAs has been demonstrated in eukaryotic organisms [27]. In recent years, with the rapid development and wide application of RNA sequencing [9], researchers have successfully detected more than 25000 types of circRNA in human fibroblast cells and proposed that circRNAs from exons and introns could be highly stable, and formed as conserved products after RNA splicing.

CircRNAs are gaining increasing attention in the field of RNA due to the following reasons: (1) most circRNAs are the products of exons, and some are directly formed by introns; (2) circRNAs are extensively found in mammalian cells, and sometimes, there are over 10 times more circRNAs than linear RNAs [28]; (3) circRNAs produced by a special variable shear have a certain organization, sequence, and disease specificity, and they are found in the cytoplasm of eukaryotic cells, but the circRNAs contained in introns are evident in nucleic acids [29]; (4) most circRNAs are conserved [9]; (5) unlike traditional linear molecules that include a $3^{\prime}$ head and $5^{\prime}$ tail, circRNAs have a closed ring structure and cannot be degraded easily by exonuclease RNase R, and hence they are more stable than linear RNA species; and (6) circRNAs have a high amount of MREs and can act as endogenous competitive RNAs and serve as natural microRNA "sponges," and thus they can induce the expression of miRNA target genes $[12,16]$.

Although there has been minimal direct evidence of a correlation between circRNAs and PE, studies on miRNAs in PE have been widely reported. Their findings suggested that miRNAs may have lost control during the process of developing the placenta, fetus, and environment of spiral arteries in the uterus [30,31]. Several research groups that analyzed miRNA expression in placental tissue found that the expression of gene transcription groups was significantly different in patients with PE $[32,33]$. In addition, with the use of qRT-PCR or high-throughput technology, researchers have found that the expression of miRNAs (miR- 
29a-5P, miR-103, miR-130b, miR-181a, miR-342-3p, and miR-574-5p) was associated with a high risk of PE, and previous studies have reported that miR-29a-5p is intimately related to PE $[33,34]$.

On the basis of bioinformatics analysis, the miRNA recognition elements (MREs) of hsa_circ_0001855 and hsa_circ_0004904 were hsa-miR-138-5p, hsa-miR-30c-1-3p, hsamiR-623, hsa-miR-30c-2-3p, hsa-miR-134-3p, hsa-miR-29a-5p, and hsa-miR-765, which all target PAPP-A. Our results showed that the expression levels of hsa_circ_0001855 and hsa circ_0004904 were increased significantly in patients with PE compared with the control group. More importantly, the expression levels of PAPP-A were higher in patients with PE compared to healthy pregnant women. These results implied that hsa_circ_0001855 and hsa_circ_0004904 may act as sponges of their MREs and then block the inhibition of MREs on their target mRNA of PAPP-A, thereby mediating the regulation of plasma PAPP-A protein expression in the pathogenesis of PE. PAPP-A combined with hsa_circ_0001855 and hsa circ_0004904 can be used as a potential early biomarker for predicting PE with an AUC of 0.940 (95\% CI $0.869-1.000$ ), sensitivity of $86.67 \%$, and specificity of $96.67 \%$.

The biological effects of PAPP-A play an important role in targeting the IGF axis. The IGF axis is composed of insulin-like growth factors, including the IGF binding proteins (IGFBPs) and IGFBP hydrolases [35, 36]. Protein hydrolysis of IGFBP splits and releases IGF. The effects of IGF-I are mediated through the IGF-I receptor by complex interactions with multiple IGFBPs. PAPP-A mediates the increase in bioactive IGF-I. IGF-I likely contributes to the proliferation and migration of endovascular extravillous trophoblast cells [37].

Overall, we screened differentially expressed circRNAs between normal and PE samples in this study and selected 18 circRNAs as representatives for validation. We also validated PAPP-A, a protein that may be closely related to hsa_circ_0001855 and hsa_circ_0004904. PAPP-A combined with hsa_circ_0001855 and hsa_circ_0004904 could be used as a potential early biomarker for predicting PE.

This study has some limitations. First, the sample size was small because our study included pregnant women before the $20^{\text {th }}$ week of gestation and because of the difficulty in obtaining specimens. What's more? The samples were not matched for BMI because the PE samples before 20 weeks' gestation were not easy to acquire when already matched with age and gestation. Previous literature showed no correlation between PAPP-A and BMI [38]. When a multiple regression analysis was performed including gender, age, BMI, waist-hip ratio, homoeostasis model assessment of insulin resistance (HOMA-IR), adiponectin and leptin as confounders, PAPP-A was independently correlated with adiponectin and leptin in cardiovascular disease. Moreover, we needed to verify the miRNAs that were related to circRNAs and PAPP-A. This verification would more clearly explain the pathogenesis of PE and would help us find suitable early prediction biomarkers. In the future, we will carry out these experiments in multiple centers with a larger number of subjects.

\section{Acknowledgements}

We thank all the pregnant women who participated in our study and the research nurses at Guangzhou Women and Children's Medical Center.

This study was supported by the Natural Science Fund of Guangdong Province (2014A030313004), the Science and Technology Fund of Guangzhou (201300000135 and 201707010019), and the Science and Technology Fund of Guangdong Province (2016A020218004). The sponsors had no role in the design and conduct of the study, the collection, analysis, and interpretation of the data, in the preparation, review, or approval of the manuscript, or the decision to submit the manuscript for publication.

\section{Disclosure Statement}

The authors declare that they have no conflict of interests. 


\section{Cellular Physiology Cell Physiol Biochem 2018;46:2576-2586 \begin{tabular}{l|l} 
DOI: 10.1159/000489685 & $\begin{array}{l}\text { O 2018 The Author(s). Published by S. Karger AG, Basel } \\
\text { www.karger.com/cpb }\end{array}$
\end{tabular}}

Jiang et al.: CircRNA and PAPP-a in Preeclampsia

\section{References}

1 Magee LA, Pels A, Helewa M, Rey E, von Dadelszen P, Audibert F, Bujold E, Côté AM, Douglas MJ, Eastabrook G, Firoz T, Gibson P, Gruslin A, Hutcheon J, Koren G, Lange I, Leduc L, Logan AG, MacDonell KL, Moutquin JM, Sebbag I: The hypertensive disorders of pregnancy. Best Pract Res Clin Obstet Gynaecol 2015;29:643-657.

-2 Antwi E, Groenwold R, Janssen K, Browne J, Klipstein-Grobusch K, Agyepong I, Koram K, Franx A, Grobbee D: PP081. Predictors of pregnancy induced hypertension in an urban low resource setting. Pregnancy Hypertens 2013;3:97.

-3 Steegers EA, Von DP, Duvekot JJ, Pijnenborg R: Pre-eclampsia. Lancet 2010;376:631-644.

4 Gao H, Liu C, Lin P, Xu L, Li X, Chen Y, Cheng B, Li A, Liu S: Effects of GSTP1 and GPX1 Polymorphisms on the Risk of Preeclampsia in Chinese Han Women. Cell Physiol Biochem 2016;39:2025-2032.

-5 Liu S, Li X, Wang J, Ji J, Liu J, Lin Y, Jia X, Song W, Wu C, Li L: The rs9932581 and rs1049255 Polymorphisms in CYBA is not Associated with Preeclampsia in Chinese Han Women. Cell Physiol Biochem 2016;39:14718.

6 Ren X, Guo M, Liu C, Huang T, Li Q Han M, Song W, Tang X, Liu S: A Case-Control Study Indicates that no Association Exists Between Polymorphisms of IL-33 and IL-1RL1 and Preeclampsia. Cell Physiol Biochem 2016;38:1406-14.

7 Huang QT, Chen JH, Zhong M, Hang LL, Wei SS, Yu YH: Chronic Hepatitis B Infection is Associated with Decreased Risk of Preeclampsia: A Meta-Analysis of Observational Studies. Cell Physiol Biochem 2016;38:1860-8.

-8 Qian Y, Lu Y, Rui C, Qian Y, Cai M, Jia R: Potential Significance of Circular RNA in Human Placental Tissue for Patients with Preeclampsia. Cell Physiol Biochem 2016;39:1380-90.

-9 Jeck WR, Sorrentino JA, Wang K, Slevin MK, Burd CE, Liu J, Marzluff WF, Sharpless NE: Circular RNAs are abundant, conserved, and associated with ALU repeats. RNA 2013;19:141-157.

10 Suzuki H, Zuo Y, Wang J, Malhotra A, Mayeda A: Characterization of RNase R-digested cellular RNA source that consists of lariat and circular RNAs from pre-mRNA splicing. Nucleic Acids Res 2006;34:e63.

11 Suzuki H, Tsukahara T: A view of pre-mRNA splicing from RNase R resistant RNAs. Int J Mol Sci 2014;15:9331-9342.

12 Hansen TB, Jensen TI, Clausen BH, Bramsen JB, Finsen B, Damgaard CK, Kjems J: Natural RNA circles function as efficient microRNA sponges. Nature 2013;495:384-388.

13 Ashwal-Fluss R, Meyer M, Pamudurti NR, Ivanov A, Bartok O, Hanan M, Evantal N, Memczak S, Rajewsky N, Kadener S: CircRNA Biogenesis Competes with Pre-mRNA Splicing. Molecular Cell 2014;56:55-66.

14 Li Z, Huang C, Bao C, Chen L, Lin M, Wang X, Zhong G, Yu B, Hu W, Dai L, Zhu P, Chang Z, Wu Q, Zhao Y, Jia Y, Xu P, Liu H, Shan G: Exon-intron circular RNAs regulate transcription in the nucleus. Natur Struct Mol Biol $2015 ; 22: 256-264$.

15 Zhang Y, Zhang XO, Chen T, Xiang JF, Yin QF, Xing YH, Zhu S, Yang L, Chen LL: Circular intronic long noncoding RNAs. Molecular Cell 2013;51:792-806.

16 Memczak S, Jens M, Elefsinioti A, Torti F, Krueger J, Rybak A, Maier L, Mackowiak SD, Gregersen LH, Munschauer M, Loewer A, Ziebold U, Landthaler M, Kocks C, le Noble F, Rajewsky N: Circular RNAs are a large class of animal RNAs with regulatory potency. Nature 2013;495:333-338.

-17 Cocquerelle C, Mascrez B, Hétuin D, Bailleul B: Mis-splicing yields circular RNA molecules. Faseb J 1993;7:155-160.

18 Cross JC, Werb Z, Fisher SJ: Implantation and the placenta: key pieces of the development puzzle. Science 1995;266:1508-1518.

19 Mikat B, Zeller A, Scherag A, Drommelschmidt K, Kimmig R, Schmidt M: $\beta$ hCG and PAPP-A in first trimester: predictive factors for preeclampsia? Hypertens Pregnancy 2012;31:261-267.

20 Dane B, Dane C, Kiray M, Cetin A, Koldas M, Erginbas M: Correlation between First-Trimester Maternal Serum Markers, Second-Trimester Uterine Artery Doppler Indices and Pregnancy Outcome. Gynecol Obstet Invest 2010;70:126-131.

21 Smith GC, Stenhouse EJ, Crossley JA, Aitken DA, Cameron AD, Connor JM: Early pregnancy levels of pregnancy-associated plasma protein a and the risk of intrauterine growth restriction, premature birth, preeclampsia, and stillbirth. J Clin Endocrinol Metabol 2002;87:1762-1767.

-22 Hourrier S, Salomon LJ, Dreux S, Muller F: Screening for adverse pregnancy outcome at early gestational age. Clin Chim Acta 2010;411:1547-1552. 


\section{Cellular Physiology Cell Physiol Biochem 2018;46:2576-2586 \begin{tabular}{l|l} 
DOI: 10.1159/000489685 & $\begin{array}{l}\text { O 2018 The Author(s). Published by S. Karger AG, Basel } \\
\text { www.karger.com/cpb }\end{array}$
\end{tabular}}

Jiang et al.: CircRNA and PAPP-a in Preeclampsia

23 Barrett SL, Bower C, Hadlow NC: Use of the combined first-trimester screen result and low PAPP-A to predict risk of adverse fetal outcomes. Prenatal Diagnosis 2008;28:28-35.

24 Krantz DL, Simpson JL, Thom E, Zachary J, Hallahan TW, Silver R, Pergament E, Platt LD, Filkins K, Johnson A, Mahoney M, Hogge WA, Wilson RD, Mohide P, Hershey D, Wapner R: First Trimester Maternal Serum Biochemistry and Fetal Nuchal Translucency Screening (BUN) Study Group: Association of extreme firsttrimester free human chorionic gonadotropin-beta, pregnancy-associated plasma protein A, and nuchal translucency with intrauterine growth restriction and other adverse pregnancy outcomes. Am J Obstet Gynecol 2004;191:1452-1458.

-25 Roberts JM, Pearson GD, Cutler JA, Lindheimer M, NHLBI Working Group on Research on Hypertension During Pregnancy: Summary of the NHLBI Working Group on Research on Hypertension During Pregnancy. Hypertens Pregnancy 2003;41:437-445.

-26 Valente AM, Economy KE: Cardiology Patient Page. Preeclampsia. Circulation 2013;128:344-345.

-27 Wang PL, Bao Y, Yee MC, Barrett SP, Hogan GJ, Olsen MN, Dinneny JR, Brown PO, Salzman J: Circular RNA Is Expressed across the Eukaryotic Tree of Life. Plos One 2014;9:e90859.

28 Salzman J, Gawad C, Wang PL, Lacayo N, Brown PO: Circular RNAs Are the Predominant Transcript Isoform from Hundreds of Human Genes in Diverse Cell Types. Plos One 2012;7:e30733.

29 Zhang XO, Wang HB, Zhang Y, Lu X, Chen LL, Yang L: Complementary Sequence-Mediated Exon Circularization. Cell 2014;159:134-147.

-30 Mouillet JF, Ouyang Y, Coyne CB, Sadovsky Y: MicroRNAs in placental health and disease. Am J Obstet Gynecol 2015;213:163-172.

-31 Miura K, Ai H, Murakami Y, Tsukamoto O, Hasegawa Y, Abe S, Fuchi N, Miura S, Kaneuchi M, Masuzaki H: Circulating chromosome 19 miRNA cluster microRNAs in pregnant women with severe pre-eclampsia. J Obstet Gynaecol Res2015;41:1526-1532.

-32 Noack F, Ribbat-Idel J, Thorns C, Chiriac A, Axt-Fliedner R, Diedrich K, Feller AC: miRNA expression profiling in formalin-fixed and paraffin-embedded placental tissue samples from pregnancies with severe preeclampsia. J Perinat Med 2011;39:267-271.

-33 Stubert J, Koczan D, Richter DU, Dieterich M, Ziems B, Thiesen HJ, Gerber B, Reimer T: miRNA expression profiles determined in maternal sera of patients with HELLP syndrome. Hypertens Pregnan 2014;33:215235.

-34 Wu L, Zhou H, Lin H, Qi J, Zhu C, Gao Z, Wang H: Circulating microRNAs are elevated in plasma from severe preeclamptic pregnancies. Reproduction 2012;143:389-397.

35 Fowlkes JL: Insulinlike growth factor-binding protein proteolysis an emerging paradigm in insulinlike growth factor physiology. Trends Endocrinol Metabol Tem 1997;8:299-306.

-36 Bayesgenis A, Conover CA, Schwartz RS: The insulin-like growth factor axis: A review of atherosclerosis and restenosis. Circul Res 2000;86:125-130.

37 Delafontaine P, Delafontaine P, Li Y, Y Li: Expression, regulation, and function of IGF-I, IGF-IR, and IGF-1 binding proteins in blood vessels. Arterioscler Thromb Vasc Biol 2004;24:435-444.

-38 Joaquín C, Granada ML, Pastor C, Castell C, Puig R, Alonso N, Serra E, Sanmartí A, Foz M, Puig-Domingo M: Pregnancy-associated plasma protein-A is related to gender and to adipocytokine levels: results of The Health Survey of Catalonia. Clin Endocrinol (Oxf) 2013;78:718-723. 